\title{
EFFICIENTLY MANAGING VIRTUAL ORGANIZATIONS THROUGH DISTRIBUTED INNOVATION MANAGEMENT PROCESSES
}

\author{
Jens Eschenbaecher \\ University of Bremen and Bremen Institute of Industrial Technology and Applied Work \\ Science (BIBA) at the University of Bremen, Hochschulring 20, D-28359 Bremen, \\ GERMANY, esc@biba.uni-bremen.de
}

Falk Graser

University of Bremen and Bremen Institute of Industrial Technology and Applied Work Science (BIBA) at the University of Bremen, Hochschulring 20, D-28359 Bremen, GERMANY, grs@biba.uni-bremen.de

Competition in the future will be characterized by an increasing meaning of customer-driven mass customization. This challenges enterprise networks to develop innovative and more flexible structures than before. The kind of organization that is considered to meet those challenges in the best possible way is the Virtual Organization. To successfully stand the competition, Virtual Organization need clear governmental structures guiding them though their collaborative processes. This paper discusses the Distributed Innovation Management (DIM) concept as an instrument to successfully govern innovation processes in Virtual Organization.

\section{INTRODUCTION}

Virtual Organizations (VO) offer a dynamic organisational form to meet the challenges of future competition and better distributed innovation management performance. Distributed Innovation Management is defined as the process of managing innovation within and across groups of organizations joining to co-design and co-produce products and co-service the customer's needs (Duschek 2002). Their temporary, flexible and dynamic nature supports the necessity to integrate different enterprises quickly for realizing common business objectives [Sydow 2001]. Whatever these business objectives may be, their common denominator is their innovative character. Creating new ideas, transforming them into a product or service, and bringing them successfully to the market is a challenge that is difficult to manage already within single enterprises where several players within one singular organization need to be streamlined to a common objective. Within a 
collaborative network, the success of innovation processes depends highly on an efficient network government: Several players within several different organizations, sharing different processes, company cultures, and information systems need to be harmonized to successfully realize an innovative idea (Gassmann and Zedtwitz 2002). Developing and implementing an innovation management system in a VO is a crucial process, not only for the reasons just mentioned, but also for time-to-market reasons. Already today, competition leaves insufficient time for organizations to iteratively optimise new processes within a non-competitive environment; vice versa processes must work reliably at once to ensure achievement of the companies' common objectives.

This paper will take a three step approach to discuss how the concept of Distributed Innovation Management can be applied for governing a Virtual Organization. First, it will expose the basic concepts of the Virtual Breeding Environment as an incubator for VO and Distributed Innovation Management, and will eventually give an integrated life-cycle schema especially regarding these two concepts. Second, it will derive recommendations for successfully implementing Innovation Management Processes, and third, it will state a couple of findings summarizing and prospectively reviewing the paper's contents.

\section{STREAMLINING ENTERPRISES FOR SUCCESSFUL INNOVATION}

\section{The Virtual Breeding Environment}

A Virtual Breeding Environment creates a community of occasionally collaborating companies. The community ensures that the partners apply methods and procedures to ensure a certain quality standard. The term virtual breeding environment was recently developed by Camarinha-Matos and Afsarmanesh (2003). Basically, a VBE supports the exploitation of local competencies and resources by an agile and fast selection of the most adequate set of partners for each innovation project. Consequently if a business opportunity has been identified by one VBE member a virtual organisation can be created rather quickly. More information about the breeding environment can be found in (Camarinha-Matos 2004).

\section{State of the art}

The concept of Innovation Management is crucial for companies and collaborative networks. Companies are also required to collaborate with other organisations, because many of them do not possess all the required skills or necessary resources to innovate (DiMAN, 2002). However, innovation activities often cannot reap the desired fruits their i mplementation promises. Most researchers agree that between $50-80 \%$ of innovation fails to have any impact on organisational goals. Some surveys' results are showed in table 2-3.

\begin{tabular}{|c|c|c|c|c|c|c|}
\hline Source & $\begin{array}{c}\text { Strebel, } \\
\text { P. }\end{array}$ & $\begin{array}{c}\text { Rothwell, } \\
\text { R. }\end{array}$ & $\begin{array}{c}\text { Hammer, } \\
\text { M. }\end{array}$ & Jaikumar & Field, T. & $\begin{array}{c}\text { Burnes, } \\
\text { B. }\end{array}$ \\
\hline Percentage & $60 \%$ & $80 \%$ & $50-70 \%$ & $50-75 \%$ & $73 \%$ & $70-80 \%$ \\
\hline
\end{tabular}

Table 1: Percentages of failure for innovation projects in organisations [Eschenbaecher 2004] 
An organisation typically can invest between $0.01 \%$ and $20 \%$ of its annual turnover in innovation. The rate of investment can depend on whether the organisation is a corporate "shooting star" where investment can be as high as $20 \%$ or "cash cow" where it can be as low as $0.5 \%$. A recent survey of European companies stated that their expenses on innovation have an average of $4 \%$. This fact implies, according to the percentages of failure for innovation projects, that there is a big amount of wasted investment that will not lead to any growth or increase in efficiency. Besides the economic loss, there are also significant consequences within organisations, regarding their culture, for example, increased scepticism among employees and greater resistance to change in the future innovation projects.

\section{Evolution towards Distributed Innovation Management in networks}

The state of the art described before clearly indicates the need for good methodological support for Innovation Management (IM). IM has been widely discussed in the past. Throughout the last five decades, the environment in which Innovation Management is embedded changed significantly several times (Möhrle, 2003). This, of course influenced Innovation Management itself, and led to adoptions of the respective methodologies. Pavitt, Rothwell, Dogson and others have put forward more than a decade ago non-linear innovation models, such as the systems integration and networking model, or 5th generation model, that highlight implementation as a non linear process of both explicit and tacit knowledge flows among a network of firms and their suppliers and customers. (Pavitt 2003, Rothwell, 1993, Dodgson 2000); they are depicted in Figure 1.

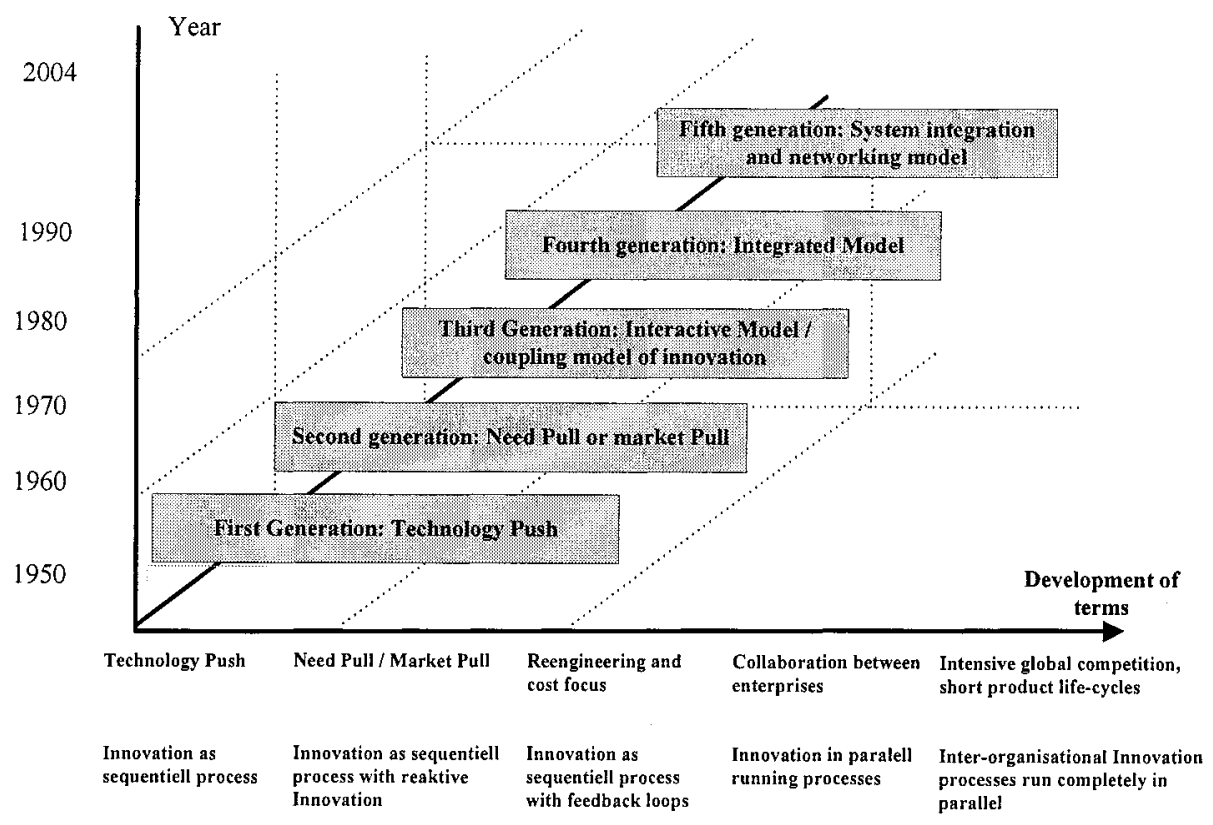

Figure: 1: Evolution of IM 
The picture includes a brief description of the dominant trend in each generation with regard to the innovation processes. DIM can be subordinated to the fifth generation "Systems integration and networking model" (Möhrle 2003). Thus, enterprise networks are conceived to undertake innovations in a collaborative and global environment, so achieving outcomes with more efficiency and effectiveness. The final aim is to fulfill customers' needs, adapting to the changing situations within the markets and improving the quality offered by the products and services. For doing this the companies must align their strategies for exchange of knowledge, ICT, processes and people. Additionally they need to have intra-organizational innovation management systems in place which need to be aligned.

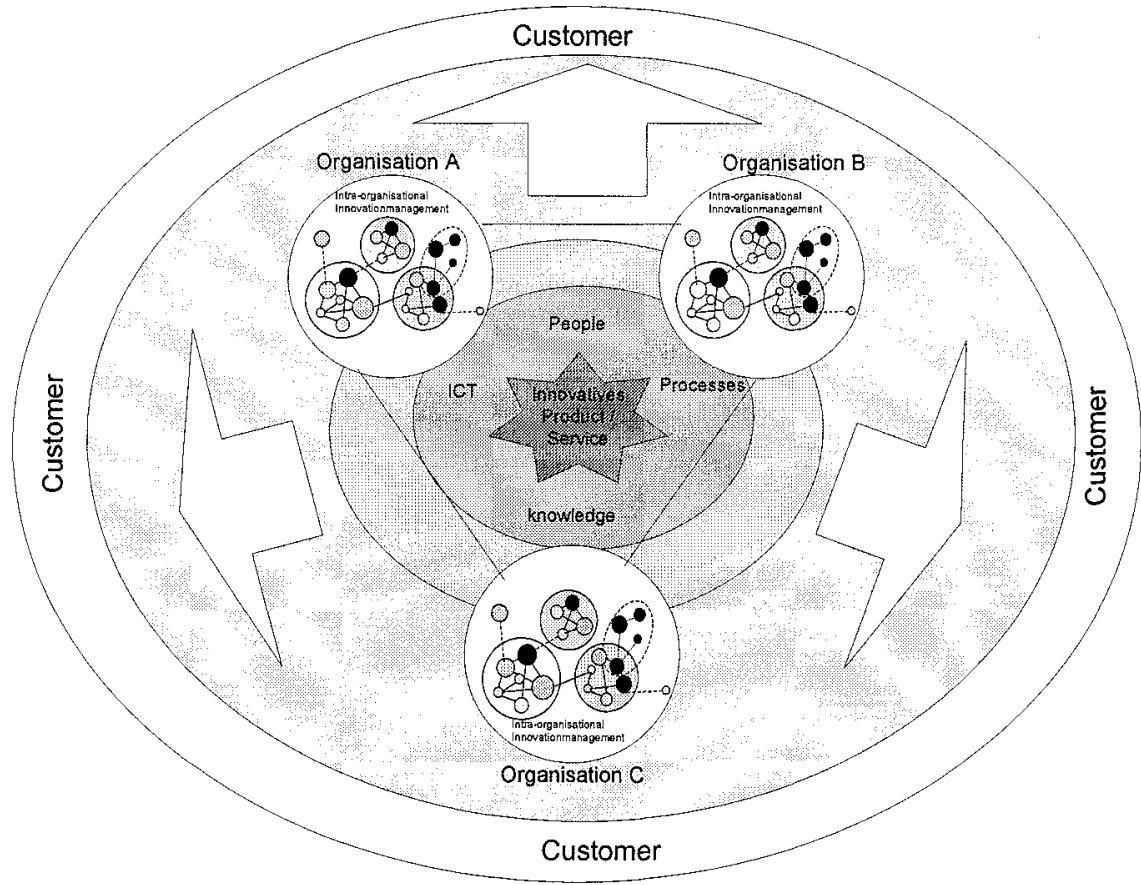

Figure 2: Distributed innovation management in collaborative networks

The network's companies must have intra-organisational innovation management systems which can be adjusted to each other. The authors structure innovation management in four levels. These are individual innovation, project innovation, collaborative innovation, and distributed innovation. The lower levels in the hierarchy are embraced by the distributed concept. In DIM, collaboration is extended beyond the limits of a single organization, cutting across the enterprise network.

\section{An integrated Life-Cycle schema for the Virtual Organization}

Figure 3 shows how the concept of the Virtual Breeding Environment is embedded into the life-cycle of a VO. When the VBE created an operable VO, the partners are 
ready to realize the innovative product and service that is objective of the partners involved. That objective represents the "Virtual Centre" of the life-cycle, to that all actions need to be adjusted.

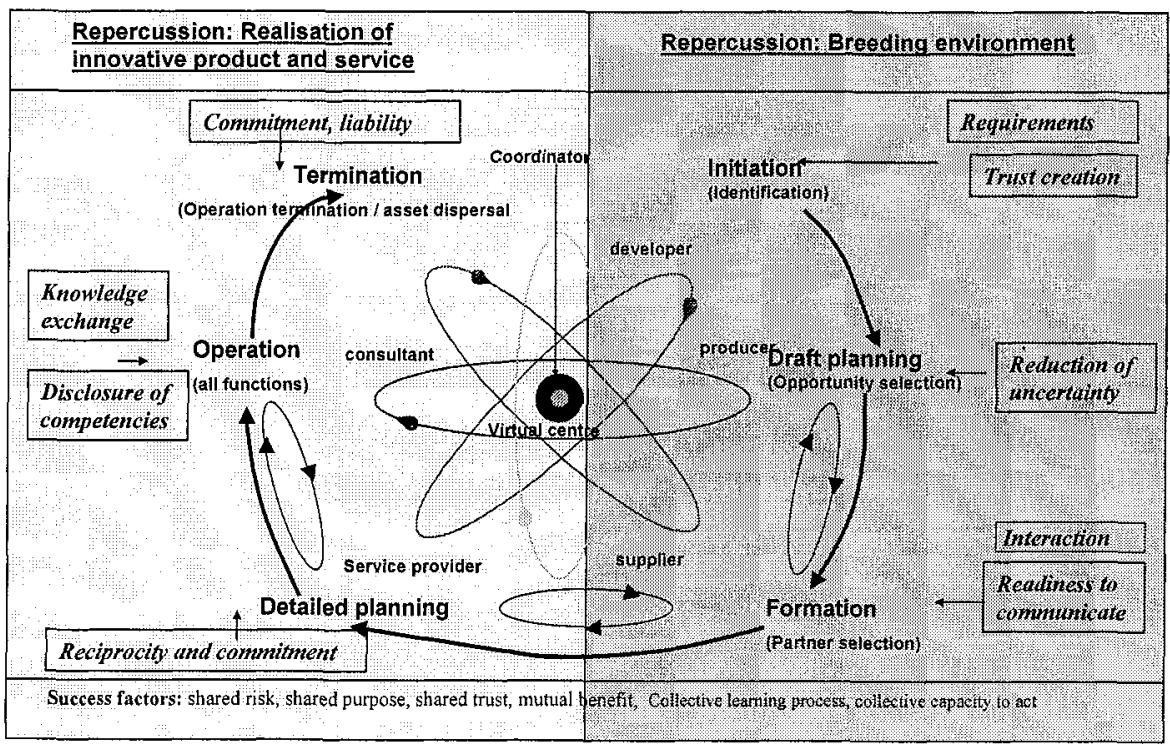

Figure 3: Requirements and success factors in the VO life-cycle

\section{RECOMMENDATIONS FOR DIM IMPLEMENTATION}

\section{Industrial case studies}

The results presented in this section are based on the AIT Implant project and some follow-up empirical studies. Additionally information can be found in Segarra (1999), Eschenbaecher und Cocquebert (1999) as well as recent case studies (Behnken 2004, Gerken 2004). Behnken (2004) illustrates different cases from the aeronautical and furniture industry whereas Gerken shows a distributed innovation management case from Porsche. The cases have clearly shown the need for a methodology which supports the management of distributed innovation processes within collaborative networks.

The case studies show that there is a high interest in tools and mechanisms to better govern innovation projects (compare Eschenbaecher und Hahn 2004).

\section{Collaboration concept}

The concept of collaboration has a major impact on distributed innovation management. Collaboration is characterised by three main aspects.

- Co-ordination by using

- Transparent structure of responsibilities, defined control mechanisms, power structures, structuring and governing phase model, definition of organisational forms of virtual teams, steering 
committee as project controlling and external support by consultants or non-team members.

- Communication by using

- Portal structure to save, open and revise documents, e-mail, calendar, news editor, quick links, status window, category definition

- Cooperation with

- Subscription opportunity,

- Web-browser user interface (24 hours availability)

The user process and the users, which collaboratively conduct the innovation process, are in the center of the framework. The model splits the innovation process into specific, discrete phases. Each phase is concluded by a review that delivers one of the two following results:

- Entering the next phase is cleared by accepting the previous' phases results, or

- The previous phase's results are rejected forcing the process back into the previous phase for improvement.

These iterative recursions separate the model from traditional, linear innovation models. Hence, this model is a non-linear one. Within the phase's context, assessment, preparation, achieving and auditing many parallel activities take place. Every phase is finished by a review organised by an independent group of experts deciding whether the activities should be continued or not. This can be an internal management board, reviewers of a funding body or a steering committee of a distributed team. Furthermore the innovation process is separated in the two main stages innovation planning and innovation introduction. These areas are governed by project teams which co-ordinate the project. This methodology shows that conducting a distributed innovation management activity within a network makes a substantial effort in co-ordination, co-operation and communication necessary. The authors propose that the optimal selection and strategic implementation of innovation methodologies describing necessary efforts and suggest an approach for application of innovation methodology in organizations.

\section{Web-based implementation}

The extension of the basic conceptual ideas can be conceived as a result of the new opportunities provided by internet-based web-portals. The innovation management methodology has been tested within a large user case (see Eschenbaecher 2004). Altogether 55 o rganisations participated in a s tudy a bout their $j$ udgement a bout a web-based distributed innovation methodology (www.expide.org/ecolead). The following figure shows the portal. The main result was that all the testing organisations agreed that a web-based DIM approach is the appropriate way to support innovation management in virtual organisations. 


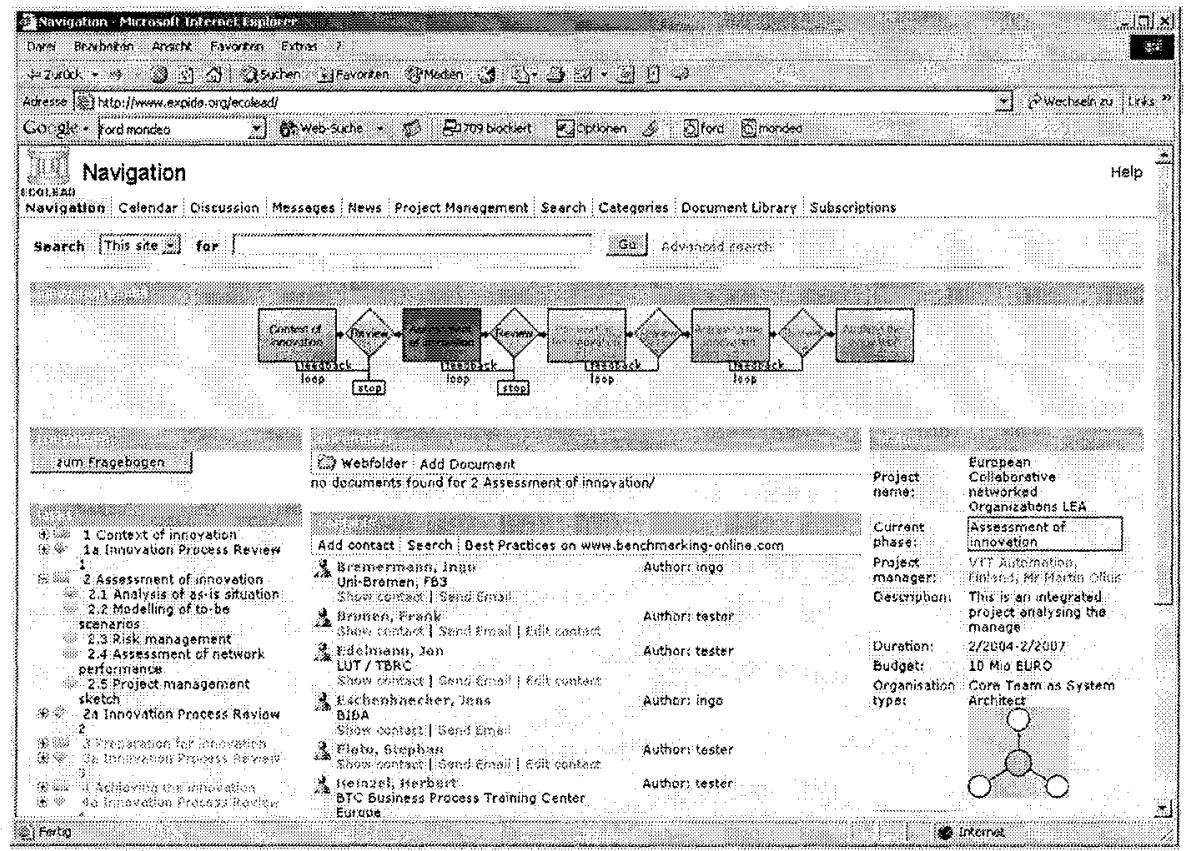

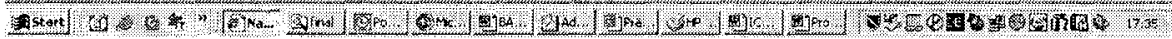

Figure 4: Web based distributed innovation management model

\section{SUMMARY AND FINDINGS}

Distributed innovation management will become a decisive task for Virtual Organizations and it is not sufficiently implemented. This is based on the large set of requirements shown and the missing common strategy development for the overall network. Furthermore the paper has presented a DIM approach considering the need to create a distributed innovation management system. The DIM portal has been validated by a sufficient user group and has been tested in various case studies. It is expected that innovation management in virtual organisations will become a major issue in future collaborate networks

\section{REFERENCES}

1. Camarinha-Matos, Luis, Afsarmanesh, Hamideh: Elements of a base VE infrastructure; to appear in International Journal of Computer Integrated Manufacturing, 2003.

2. Camarinha-Matos, Luis, Afsarmanesh, Hamideh: New collaborative organiszations and their Research needs, In: Processes and Foundations for virtual organizations, Kluwer Academic Publishers, Boston/Dordrecht/London, 2004, p. 3-12.

3. Cascio, Walter: Virtual workplaces: implications for organizational behaviour. In C.L. Cooper \& D.M. Rousseau (Eds.), The virtual organization. Trends in Organizational Behaviour, Vol 6, pp. 114. Chichester: John Wiley \& Sons, 1999.

4. Cormican, Kathryn: Product Innovation Management for Networked Organisations, Galway 2001, PHD-Thesis.

5. Dodgson M: The Management of Technological Innovation, Oxford: Oxford Univ Press, 2000. 
Drucker, P. F.: "Innovation and Entrepreneurship: Practices and principles", Heinemann, London, 1985

Drucker, P. F.: „Innovations-Management für Wirtschaft und Politik”, Econ Verlag, Düsseldorf und Wien, 3. Auflage, 1986

Duschek, S.: Innovation in Netzwerken - Renten - Relationen - Regeln, Wiesbaden 2002, PHD Thesis.

Eschenbaecher, Jens; Hahn, Axel: Approach for implementing distributed innovation management in collaborative industrial networks, Forthcoming Proceedings of the ICE 2004 conference in Sevilla, 2004

Gassmann, O liver, v on Z edtwitz, M aximilian: O rganising V irtual R\&D teams. In: R\&D management, Vol. 33, No. 3, pp. 243-262.

Hauschildt, Jörg.: Innovationsmanagement, Verlag Franz Vahlen, München, 1993

Hess, Thomas: Netzwerkcontrolling - Instrumente und ihre Werkzeugunterstützung. Deutscher Universitätsverlag $\mathrm{GmbH}$, Wiesbaden, 2002.

Jarvenpaa, Stephan, Leidner, Dieter: Communication and trust in global virtual teams. In: Journal of Computer-Mediated Communication, Vol. 3, No. 4, 1998, p.1-38.

Lorenz, G./Veit, E.: „Die treibende Kraft: neue Technologien“, in Staudt, E. (Hrsg.): „Das Management von Innovationen" FAZ, 1986, p.295

Marshall, Paul, McKay, James, \& Burn, Janice: The Three S's of Virtual Organisations: Structure, Strategy and Success Factors. In: Hunt \& Davnes (Eds.), E-Commerce and V-Business (pp. 171192): Butterworth Heinemann, 2001.

McDonough III, Eve, Kahn, Kabal \& Barczak, Gerd: An investigation of the use of global, virtual, and collocated new product development teams. The Journal of Product Innovation Management Vol 18, Heft 2, 2001 110-120.

Mertens, Peter; Faisst, Wolfgang: Virtuelle Unternehmen, In: Wirtschaftswissenschaftliches Studium, Heft 6, 1996, S. 280-285.

Möhrle, M. G.: "Der richtige Projekt-Mix", Springer-Verlag, Berlin, 1999

O'Sullivan, David.; Cormican, Kathryn.: A Collaborative Knowledge Management Tool for Product Innovation Management, in: Int. Journal of Technology Management, Vol. 26, No. 1, 2003, S. 5367.

Pavitt K (2003) The process of innovation, SPRU working paper no.89, Brighton: Univ of Sussex

Schuh, Günter, Katzy, Bernhard and Milarg, Klaus: Wie virtuelle Unternehmen funktionieren: Der Praxistest ist bestanden, In: Gablers magazin, No. 3, 1997, p. 8-11

Schumpeter, 3.: „Theorie der wirtschaftlichen Entwicklung“, 3. Aufl., Leipzig, 1931

Segarra, G. (1999), The advanced information technology innovation roadmap. Computers in Industry, Volume 40, Issues 2-3, November 1999, Pages 185-195

Rothwell R (1994) Towards the fifth generation innovation process, International Marketing Review, pp7-31.

Sydow, Jörg: Management von Netzwerkorganisationen - Zum Stand der Forschung. In: Jörg Sydow (Hrsg.), Management von Netzwerkorganisationen (pp 293-329): Verlag Dr. Th. Gabler GmbH: Wiesbaden 2001 . 